\title{
General practitioner attitudes to the care of people with epilepsy: an examination of clustering within practices and prediction of patient-rated quality of care
}

\author{
Ajay K Thapar*1,2 and Martin O Roland ${ }^{3}$
}

Address: ${ }^{1}$ School of Psychology, Cardiff University, Tower Building, Park Place, Box 901, Cardiff, UK, ${ }^{2}$ Taff Riverside Practice, Riverside Health Centre, Cardiff, UK and ${ }^{3}$ National Primary Care Research and Development Centre, University of Manchester, Manchester, UK

Email: Ajay K Thapar* - thaparak@cf.ac.uk; Martin O Roland - m.roland@man.ac.uk

* Corresponding author

Published: 0I March 2005

BMC Family Practice 2005, 6:9 doi:10.1 186/147/-2296-6-9
Received: 19 July 2004

Accepted: 01 March 2005

This article is available from: http://www.biomedcentral.com/147I-2296/6/9

(c) 2005 Thapar and Roland; licensee BioMed Central Ltd.

This is an Open Access article distributed under the terms of the Creative Commons Attribution License (http://creativecommons.org/licenses/by/2.0), which permits unrestricted use, distribution, and reproduction in any medium, provided the original work is properly cited.

\begin{abstract}
Background: There is wide variation in the quality of care provided by primary care practices to individuals with chronic illnesses. Individual doctor attitudes and interest have been demonstrated to influence patient outcomes in some instances. Given the trend towards larger practices and parttime working, continuity of care is likely to fall and thus practice-based rather than individual general practitioner attributes and attitudes are likely to become increasingly important. The aim in this paper was to examine the extent to which individual general practitioner (G.P.) attitudes to the care of people with epilepsy cluster within practices and predict patient-rated quality of care.
\end{abstract}

Methods: The sample consisted of 1255 people with active epilepsy (a recent seizure or on anticonvulsant medication for epilepsy) and 199 GPs from 82 general practices. Measures of GP attitudes (a 17-item GP attitudes questionnaire) and patient-rated quality of epilepsy care were obtained. 1210 individuals completed initial questionnaires and 975 patients filled in final questionnaires one year later. Responses were achieved from 64 practices (83\% of total) and II5 GPs (60\% of total).

Results: 2 main factors were found to underlie GP attitudes to the care of people with epilepsy and these demonstrated clustering within practices "epilepsy viewed as a primary care responsibility" (Eigenvalue 3.98, intra-class correlation coefficient (ICC) 0.40 ), and "medication skills"(Eigenvalue 2.74, ICC 0.35). GP-rated scores on "epilepsy care being a primary care responsibility" were a significant predictor of patient-rated quality of GP care $(p=0.031)$. Other contributory factors were seizure frequency $(p=0.044)$, and patient-rated "shared decision making" ( $p=0.022)$.

Conclusion: Specific general practitioner attitudes to the care of people with epilepsy cluster within practices and are significantly associated with patient-rated quality of epilepsy care. It is important to take these findings into consideration when planning primary care interventions to ensure people with epilepsy receive the benefits of available medical and surgical expertise. 


\section{Background}

There is wide variation in the quality of care provided by primary care practices to individuals with chronic illnesses [1]. Individual doctor attitudes and interest have been demonstrated to influence patient outcomes in some instances $[2,3]$ and it has been argued that specific attitudes are more predictive of behaviour than general attitudes[4]. For chronic diseases, in line with the distinction proposed by Katz [5], these doctor attitudes may be separated into perceptions of knowledge, skills and personal preferences. The importance of these specific doctor attitudes on patient outcomes is however largely unknown.

There is a marked trend to larger partnerships in primary care practices and more flexible working practices. It is likely, therefore, that continuity of care will continue to fall, and that patient experience of care of a particular condition will be based on contact with more than one general practitioner [6]. Thus practice-based rather than individual general practitioner (GP) attributes and attitudes are likely to become increasingly important. The extent to which GP attitudes to specific chronic conditions cluster within practices, is however currently unknown. There is evidence that where attitudes within a group are shared this enhances the influence of individual attitudes on behaviour [7]. Thus, on the basis of this observation, if attitudes are shared by general practitioners within practices, these group-based attitudes are then more likely to influence GP behaviour and the quality of care provided by the clinician.

In the next few years there is likely to be considerable reorganisation of the way in which epilepsy care within primary care is delivered, with GPs taking on a more active role in providing care. Information on how individual general practitioners view and value their role in providing epilepsy care is considered as important [8]. However, what may be more important is whether or not these views are shared within the practice and if these attitudes influence the quality of care provided by the practice. If this is the case, then taking GP attitudes in a given practice into account will be crucial in deciding how primary care services for people with epilepsy are best organised and improved.

In this paper, data from a completed community-based study on people with epilepsy are used to examine the following questions:

1. To what extent do individual general practitioner attitudes to the care of people with epilepsy cluster within practices?
2. Do general practitioner attitudes predict how people with epilepsy rate the quality of the general practitioner care of their epilepsy?

\section{Methods}

General practitioners and adults with epilepsy taking part in an intervention study in Greater Manchester provided information for this study. The results of the intervention study (a prompt and reminder card for general practitioners to complete, held by patients or placed in their medical records and used opportunistically over the course of a year) have been reported [9]. No group differences in patient rated outcome measures were found for the intervention study [9].

Ethical approval was obtained in the 4 areas of Greater Manchester from where patients were approached. The patients who consented to participate in the study had their medical records examined to extract data on recording of clinical information about epilepsy and other markers of quality of care. Patients were also sent questionnaires for self-completion. These included both a generic quality of life measure- the EUROQOL 5D[10] and a disease specific quality of life and quality of care measure, the "Living with Epilepsy" questionnaire which has been psychometrically tested and shows good reliability and validity [11]. Self-rated seizure frequency (included in the "Living with Epilepsy" questionnaire) was based on the response to a question "How many epileptic attacks have you had in the past year" with the 3 response categories being "None", " Less than one a month" and "One or more a month".

General practitioners completed a 17-item GP epilepsy attitudes questionnaire at the end of the study. Responses to items such as "I feel comfortable changing the type of anti epileptic drugs in my patients" were scored using a Likert scale. The attitudes scale was developed and validated for a previous study and results reported in an earlier paper [12].

\section{Statistical analysis}

Mean practice scores for each item on the GP attitudes questionnaire were computed and significant factors underlying the grouping identified (using eigenvalues $>1.2$ and the Scree test.). Clustering of responses on the attitudes questionnaire were examined using the intraclass correlation coefficient both for individual items as well as for a mean score of responses to items loading on each of the main factors. Finally linear regression analysis with the patient-rated quality of care provided by the practice as the dependent variable and GP attitudes and other patient derived measures (such as seizure frequency, age, gender, other long term illness) as independent variables was carried out (using aggregated GP attitude and patient 
Table I: Two main extracted factors, significant factor loadings and intraclass correlation coefficients (ICC) for general practitioner attitudes within practices

\begin{tabular}{|c|c|c|}
\hline & Factor loading' & $\mathrm{ICC}^{2}$ \\
\hline \multicolumn{2}{|c|}{ Factor I: "Primary care responsibility"(Eigenvalue 3.98, $24.9 \%$ of variance explained)-mean scores } & 0.40 \\
\hline "Not too time pressured to take on epilepsy care" & 0.785 & $0.37^{* *}$ \\
\hline "GP has primary responsibility for organising follow up care" & 0.769 & 0.13 \\
\hline "Epilepsy care not too difficult to organise" & 0.767 & $0.19 *$ \\
\hline "Epilepsy care not a specialist responsibility" & 0.732 & $0.34^{* *}$ \\
\hline "Epilepsy care should be based in general practice" & 0.684 & $0.44^{* *}$ \\
\hline "Annual structured review should be carried out in primary care" & 0.657 & 0.10 \\
\hline \multicolumn{2}{|c|}{ Factor 2: "Medication skills"(Eigenvalue $2.74,17.1 \%$ of variance explained) } & 0.35 \\
\hline "Comfortable adjusting dose of medication" & 0.724 & $0.31 * *$ \\
\hline "GP responsible for adjusting treatment if more fits" & 0.718 & $0.25^{*}$ \\
\hline "Comfortable adjusting type of medication" & 0.655 & 0.17 \\
\hline
\end{tabular}

$\mathrm{p}<0.05, * * \mathrm{p}<0.01$

I (based on mean GP scores per practice)

2 (based on individual GP scores in practices with $>$ I respondent)

scores). Intervention group was adjusted for. $\mathrm{P}$ values of 0.05 and $95 \%$ confidence intervals were used to assess significance.

\section{Results}

1255 patients consented to participate in the study and 975 patients filled in final questionnaires. 199 GPs from 82 practices consented to participate in the study. Responses were obtained from 115 GPs (60\% of total) from 64 practices ( $83 \%$ of total). 29 practices had a single respondent. These practices were excluded from the analysis of attitude clustering. In this study $54 \%$ of individuals were seizure-free in the previous year ("controlled" seizures) and $46 \%$ had reported a seizure in the previous year ("uncontrolled" seizures).

\section{Factor analysis and clustering of GP attitudes}

Factor analysis with varimax rotation was undertaken on aggregate GP responses. Four factors had an eigenvalue of above 1.2. Three of these factors were selected after the scree test. Both the Kaiser-Meyer-Olkin measure of Sampling adequacy test (0.778) and Bartletts test for sphericity (Chi-square 413.7, Df 120, p < 0.0001) suggested that factor analysis was appropriate for this data set. Using guidelines for identifying significant factor loadings based on sample size from Hair et al.[13] a cut-off of 0.65 was used. Individual items within each factor were used to generate mean factor scores. These mean factor scores were normally distributed.

Responses to the 11 questions that were included in the first three factors were further examined. The aim was to detect if significant clustering of responses to these items occurred within practices. The average cluster size was 2.74 .

The results of the factor analysis and clustering of attitudes for the two main factors are listed in Table 1. The other two factors were excluded. The first excluded factor was not clinically meaningful with only two disparate items loading on it ("epilepsy care straightforward", "epilepsy patients viewed as being well-informed"). The second excluded factor explained less than $10 \%$ of variance and only had one item loading on it ("self-perceived knowledge of epilepsy").

\section{Do GP attitudes predict how patients rate the quality of GP care of their epilepsy?}

Data from 60 practices where both patient and general practitioner data were available were used in the linear regression analysis. As the data were obtained at the end of an intervention study, the intervention group was also included as an independent variable. The results of this analysis are given in Table 2. Significant predictors of patient-rated quality of GP care were patient seizure frequency and patient-rated "shared decision making" and GP-rated score on "epilepsy care being a primary care responsibility" (Factor 1). Recording of clinical information about epilepsy was not a significant predictor of patient-rated quality of GP care.

Some further bivariate analyses were also undertaken. Recording of clinical information about epilepsy by GPs was not significantly associated with the GP-rated score 
Table 2: Linear regression analysis: GP and patient predictors of patient rated satisfaction with GP care of epilepsy

\begin{tabular}{|c|c|c|c|c|c|c|c|}
\hline & \multicolumn{2}{|c|}{ Unstandardized Coefficient } & \multirow{2}{*}{$\begin{array}{l}\begin{array}{l}\text { Standardized } \\
\text { Coefficient }\end{array} \\
\text { Beta }\end{array}$} & \multirow[t]{2}{*}{$\mathrm{t}$ value } & \multirow[t]{2}{*}{ Sig. } & \multicolumn{2}{|c|}{$95 \%$ Confidence intervals for $B$} \\
\hline & B & Std Error & & & & Lower bound & Upper bound \\
\hline \multicolumn{8}{|l|}{ Patient measures } \\
\hline Age & -.012 & .006 & -.19 & -1.80 & .079 & -.025 & .001 \\
\hline Gender & -.4 & .258 & -.19 & -1.55 & .128 & -.921 & .120 \\
\hline Long term health problems other than epilepsy & -.141 & .255 & -.05 & -.55 & .583 & -.655 & .373 \\
\hline Anxiety score & .051 & .028 & .24 & 1.80 & .078 & -.006 & .108 \\
\hline Depression scores & -.048 & .041 & -.17 & -1.16 & .255 &.$-|3|$ & .036 \\
\hline Ease of talking to GP about epilepsy & .392 & .348 & .13 & 1.128 & .266 & -.309 & 1.109 \\
\hline $\begin{array}{l}\text { GP takes views of epilepsy into account } \\
\text { ("shared decision making")* }\end{array}$ & .931 & .390 & .31 & 2.38 & .022 & .144 & 1.719 \\
\hline Seizure frequency* & .306 & .148 & .26 & 2.07 & .044 & .008 & .604 \\
\hline \multicolumn{8}{|l|}{ GP measures } \\
\hline $\begin{array}{l}\text { Epilepsy as primary care responsibility* } \\
\text { (factor I) }\end{array}$ & .154 & .069 & .29 & 2.23 & .031 & .015 & .294 \\
\hline Medication skills (factor 2 ) & -.033 & .059 & -.07 & -.564 & .576 & -.152 & .086 \\
\hline
\end{tabular}

Data adjusted for intervention group

$r^{2}=0.635$, adjusted $r^{2}=0.525$, standard error $=0.224$

$*$ p value $<0.05$

on epilepsy care being a primary care responsibility but was associated with seizure frequency.

\section{Discussion}

In this study two main factors ("epilepsy viewed as a primary care responsibility" and "medication skills") were found to underlie GP attitudes to the care of people with epilepsy. Responses to questions constituting these factors demonstrated a high and significant level of clustering within practices. The main factor that accounted for the largest proportion of variance, general practitioner-rated "epilepsy viewed as a primary care responsibility", significantly predicted patient-rated quality of care. Patientrated shared decision-making and seizure frequency were other significant predictors of patient-rated quality of GP epilepsy care. Recording of clinical information by GPs about epilepsy was not associated with GP attitudes to epilepsy care but was related to patient seizure frequency.

In this study general practitioner attitudes to the care of people with epilepsy were found to cluster within practices to a considerable extent. This has not previously been shown in the U.K. A recent Dutch study [14] showed that GPs working in the same partnership showed more resemblance in overall attitudes to patient care and behaviour than GPs not working in the same partnership and hypothesised that social processes in partnerships and local circumstances may be particularly relevant. The present study has quantified these intra-practice GP similarities in terms of attitudes to one specific chronic condition. Moreover the results of this study also demonstrate that certain general practitioner attitudes predict patientrated quality of care provided by the practice. The high level of clustering of GP attitudes and the effect of these attitudes on patient-rated outcomes in terms of quality of care, may have important implications in determining the effectiveness of practice level interventions in primary care. These results suggest, firstly, that when planning educational interventions, changing GP attitudes within practices should also be a key aim and, secondly, to focus on changing attitudes for the practice as a whole rather than simply for individual general practitioners. In addition, for practice level intervention studies (especially those using patient-rated quality of care as an outcome measure) an estimate of clustering of doctor attitudes as well as estimates of clustering of patient responses when carrying out power calculations should be incorporated to avoid making a Type 1 error.

There is relatively little information of the relationship of GP attitudes to patient ratings of the quality of GP epilepsy care. Existing evidence suggests that GPs with a special interest in a particular condition improves outcomes [2]. The results of the present study extend these findings by highlighting the importance of specific attitudes (accepting a key role in management) rather than perceptions of specific skills (skills in medication management) in predicting patient rated quality of care.

The results of a multilevel analysis examining patient and doctor predictors of patient satisfaction from the Netherlands [15] suggested that most of the variance in "patient 
satisfaction" scores was at the patient level (age, morbidity and previous negative experience with the GP being the main predictors) with only $5-10 \%$ of the variance in "patient satisfaction" being at the doctor level. However in that Dutch study [15], specific GP attitudes were not included as predictors and the "patient satisfaction" score was a composite score incorporating measures of accessibility, availability, humaneness of the GP and information provision. Patient-centred communication skills are known to be associated with improved patient satisfaction [16] and our analysis indeed found that patient-rated shared decision making ("GP took my views into account") was another significant predictor.

Patient ratings of the quality of care do vary according to whether individuals have controlled or uncontrolled seizures. Individuals with controlled seizures rate the quality of care provided higher than individuals with uncontrolled seizures. However why the ratings of care provided are higher is not clear as individuals with controlled and uncontrolled epilepsy differ from each other in other characteristics that may influence quality ratings apart from seizure frequency (e.g. depression scores, social functioning).

At practice level GP attitudes are not related to mean practice patient seizure frequency. Although it is likely that individual GP attitudes will be influenced by whether an individual patient has controlled or uncontrolled seizures it is not possible to empirically demonstrate this relationship, as nearly all general practitioners will see a mix of individuals with "controlled" and "uncontrolled" seizures in a given year. Their attitudes to the care of people with epilepsy will be influenced by this spectrum of epilepsy severity (and often to a greater extent by other factors including significant events with individual patients).

In terms of limitations of the results, some practices did not consent to take part in this intervention study and not all GPs who participated completed questionnaires. However there were no significant differences between practices that participated and did not participate in terms of size, average deprivation or training status [9]. Moreover responses to the GP questionnaire were received from over $80 \%$ of practices that participated and $60 \%$ of the doctors that participated. Aggregate scores were used when doctor and patient views were analysed. This will reduce variability and may result in a loss of statistical power. However given that many different patient-doctor encounters are likely within a given year this approach was the most pragmatic. Although the results were obtained at the end of an intervention study that may have influenced attitudes one of the groups in the study was a control group and no significant differences in GP attitudes between groups was found. Furthermore, results on GP attitudes in the present study were very similar to those found in a previous survey using this scale [12].

\section{Conclusion}

Specific general practitioner attitudes to the care of people with epilepsy are significantly associated with patientrated quality of epilepsy care and cluster within practices. It is important to take these findings into consideration when planning interventions and services. General practitioners need to have good knowledge and skills in the management of epilepsy and should be aware of and utilise current guidelines for good clinical epilepsy care [17-19] to fully utilize medical and surgical expertise in managing epilepsy. Recognising and addressing general practitioner attitudes to the care of people with epilepsy may be important in ensuring these goals of good epilepsy care are met.

\section{Competing interests}

The author(s) declare that they have no competing interests.

\section{Authors' contributions}

AT designed and ran the study, undertook the analysis and wrote the manuscript. MR was involved in the design and running of the study and edited the paper.

\section{Acknowledgements}

The original study was funded by the Department of Health. AT has been subsequently funded by a Health Foundation mid-career fellowship. We thank all the practices, GPs and the patients who took part and are grateful for suggestions on statistical analysis provided by Dr. Gordon Harold, Dr Kerenza Hood and Professor lan Russell. Professor Ann Jacoby, Professor lan Russell, Dr Chris Roberts, Mrs Elaine Porter, Ms Sonia Wall were involved in the original intervention study.

\section{References}

I. Campbell SM, Hann M, Hacker J, Burns C, Oliver D, Thapar A, Mead $N$, Safran DG, Roland MO: Identifying predictors of high quality care in English general practice:observational study. BMJ 200I, 323(73 I6):784-7.

2. Pringle M, Stewart-Evans C, Coupland C, Williams I, Allison S, Sterland J: Influences on control in diabetes mellitus: patient, doctor, practice, or delivery of care? BMJ 1993, 306(6878):630-4.

3. Belfiglio M, De Berardis G, Franciosi M, Cavaliere D, Di Nardo B, et al.: QuED Study Group-quality of care and outcomes in type 2 diabetes. The relationship between physicians' selfreported target fasting blood glucose levels and metabolic control in type 2 diabetes. The QuED Study Group - quality of care and outcomes in type 2 diabetes. Diabetes Care 2001 , 24(3):423-9.

4. Ajzen I, Fishbein M: Understanding attitudes and predicting social behaviour Englewood Cliffs, NJ: Prentice Hall; 1980.

5. Katz D: The functional approach to the study of attitude. Public Opinion Quarterly 1960, 24:163-204.

6. Freeman G, Hjortdahl P: What future for continuity of care in general practice? BMJ 1997, 3 I 4(7098): 1870-3.

7. Terry DJ, Hogg MA: Group norms and the attitude-behaviour relationship: a role for group identification. Personality and Social Psychology Bulletin 1996, 22:776-793.

8. Thapar AK: Epilepsy care in the community - new initiatives but old problems. British Journal of General Practice 1996, 46:37-42.

9. Thapar A, Jacoby A, Richens A, Russell I, Roberts C, Porter E, Wall S, Roland $M$ : A pragmatic randomised controlled trial of a 
prompt and reminder card in the care of people with epilepsy. Br J Gen Pract 2002, 52(475):93-8. II

10. EuroQol Group: EuroQol-a new facility for the measurement of health related quality of life. Health Policy 1990, 16:199-208.

II. Baker GA, Smith DF, Dewey M, Jacoby A, Chadwick DW: The initial development of a health-related quality of life model as an outcome measure in epilepsy. Epilepsy Res 1993, 16(1):65-81.

12. Thapar AK, Stott NC, Richens A, Kerr M: Attitudes of GPs to the care of people with epilepsy. Fam Pract 1998, I5(5):437-42.

13. Hair JF, Anderson RE, Tatham RL, Black WC: Multivariate Data Analysis. 5th edition. Prendice-Hall International Inc; 1998.

14. De Jong JD, Groenewegen PP, Westert GP: Mutual influences of general practitioners in partnerships. Soc Sci Med 2003, 57(8): $1515-24$.

15. Sixma HJ, Spreeuwenberg PM, van der Pasch MA: Patient satisfaction with the general practitioner: a two-level analysis. Med Care 1998, 36(2):212-29.

16. Stewart M, Brown JB, Donner A, McWhinney IR, Oates J, Weston WW, Jordan J: The impact of patient-centered care on outcomes. J Fam Pract 2000, 49(9):796-804

17. SIGN: Diagnosis and Management of Epilepsy in Adults : Guideline 70 Scottish Intercollegiate Network; 2003.

18. National Institute of Clinical Excellence: Epilepsy : the diagnosis and management of epilepsy in children and adults. (2nd Draft version) NICE; 2004.

19. Brodie MJ, Shorvon SD, Canger R, Halasz P, Johannessen S, Thompson P, Wieser HG, Wolf P: Commission on European Affairs: appropriate standards of epilepsy care across Europe.ILEA Epilepsia 1997, 38(I I): 1245-50.

\section{Pre-publication history}

The pre-publication history for this paper can be accessed here:

http://www.biomedcentral.com/1471-2296/6/9/prepub

\section{Publish with Bio Med Central and every scientist can read your work free of charge}

"BioMed Central will be the most significant development for disseminating the results of biomedical research in our lifetime. "

Sir Paul Nurse, Cancer Research UK

Your research papers will be:

- available free of charge to the entire biomedical community

- peer reviewed and published immediately upon acceptance

- cited in PubMed and archived on PubMed Central

- yours - you keep the copyright 